\title{
Palliative Care: An Alien Concept in Pakistan
}

Nadia Pyarali Mulji ${ }^{*}$ Sumaira Sachwani

Aga Khan University School of Nursing and Midwifery Pakistan, Pakistan

*Corresponding author: Nadia Mulji, Aga Khan University School of Nursing and Midwifery Pakistan, Pakistan, Tel: +92332302484; E-mail: nadia.mulji@aku.edu Received date: March 15, 2017; Accepted date: April 24, 2017; Published date: April 29, 2017

Copyright: @ 2017 Mulji NP. This is an open-access article distributed under the terms of the Creative Commons Attribution License, which permits unrestricted use, distribution, and reproduction in any medium, provided the original author and source are credited.

\begin{abstract}
Every living being has to die. Respecting a dying individual's personal values and preferences is a challenge. We live in a culture where family decisions are given priority over individual's wish. To address this challenge, a concept of palliative or comfort care is newly introduced in Pakistan. Palliative care is a multidisciplinary specialty that emphases on prevention and relieving suffering as well as supporting the optimal quality of life of patients and their families (Bailey, Harman, Bruera, Arnold, \& Savarese,2014). In Pakistan, the concept of palliative care is like a newborn baby who needs a lot of ethical attention in terms of patient's autonomous decision, family members' care for the patient and the medical team's professional obligations. So, in a tug of war between the medical team and the family, the patient should not suffer. I, as a nurse, would like to create a universal familiarity and awareness about palliative care and its associated ethical concerns and suggest nurse's responsibilities to promote comfort care at home.
\end{abstract}

"There is an appointed time for everything. A time to give birth and a time to die". Ecclesiastes 3:2

Keywords: Lymphoma; Palliative; Autonomy; Paternalistic

\section{Commentary}

This paper is based on a scenario of a 30 -year old young man with end-stage lymphoma. The mother wanted to do all possible interventions to treat his son. The medical team concluded that there is no further treatment option available. The physician wanted to send the patient home to spend time with his family and to prevent hospital induced complications, whereas the mother was not willing to take him home. In such situation, what would be the possible best decision for the patient who has a short expected survival time?

The analysis of the above case study highlighted different ethical issues:

\section{Patient's Autonomy Vs. Institutionalized Decision}

Firstly, the patient has the autonomy to decide for himself. His choice of staying at home and spending time with his family needs to be respected. The patient feels more secured and fearless at home rather than in the hospital. In the West, the concept of individual autonomy or decision making is very important. Billings and Krakauer explained that autonomy in the end-of-life care describes that it is one's wish that can occur in the absence of interference from the physician and the family [1]. However, in the Pakistani context, family decisions are given importance over the individual's wish. We live in a society where every individual is interdependent upon each other e.g., the elderly is morally dependent on the children; the parent has moral responsibility towards the children. Therefore, decisions are mostly institutionalized rather than autonomous. Moreover, autonomy is not apparent when patients are in a vulnerable and dependent condition.

\section{Paternalism Vs. Ethics of Care}

Secondly, the family members cannot see their loved ones in pain and when they feel that the situation is beyond their control they insist on keeping the patient in the hospital using paternalistic approach. Ekore, Bolatito, Ekore and Ajayi define paternalistic approach as imposing one's set of value on others (2012). In Ethics, paternalistic approach gives a negative impression; it can be altered by ethics of care where the family has moral responsibility to care for their loved ones. Slote defines ethics of care [2] as not only imposing one's own ideas for caring someone, and for what is good for the person cared about, but also keeping in mind the way that the person perceives the world and his relationship to it. In Pakistani context, the family fear whether they will be able to manage the patient at home. Moreover, the family feels guilty if they do not take their patient to the hospital; this might be due to their less understanding and role in futile care. Moreover, the family and physician are obliged to do aggressive treatment though there is no cure available.

\section{Non-maleficence and Justice}

Thirdly, the physician's emphasis is on early discharge to prevent the patient from hospital-acquired infection. Ferrell and Coyle define nonmaleficence as [3], to act in a way that does not cause harm or injury to others. Furthermore, the physician also has a moral obligation to care for the patient. Besides this, in our culture, dialogue on deceased matter is a taboo, and therefore nurses, physician and family avoid discussion on such matters. Furthermore, the physician also has an obligation to justify the provision of health resources to other needy patients. If a patient is occupying a bed since two months without treatment, it is not justified for the patient who requires immediate intervention.

In the above analysis, all aspects are important, respect for patient's autonomous decision, family members' care for the patient and the medical team's professional obligations. So, in a tug of war between the 
Page 2 of 2

medical team and the family, the patient should not suffer. I, as a nurse, would like to create a universal familiarity and awareness about comfort care at home. In short, a dying patient encounters care in different ethical concerns; all can be addressed by one single concept of palliative care.

\section{Palliative Care}

The World Health Organization defines palliative care as "the active total care of patients whose disease is not responsive to curative treatment" [4]. Furthermore, according to Field and Cassel [5] Institute of Medicine (IOM) emphasized that it "seeks to prevent, relieve, reduce, or soothe the symptoms of disease or disorder without affecting a cure". There are different models of palliative care like hospital-based and community-based but the best model that takes maximum care needs of the patient is home-based palliative care. It has been identified that home-based palliative service has many advantages such as reduced cost of treatment, lowered number of readmissions, improved quality of life, enhanced survival, and lessened feelings of depression (Beresford \& Kerr, 2012). Moreover, studies on palliative care proposed several benefits for patient, family and hospital [6].

\section{Palliative Care in Pakistani Context}

In Pakistan, the concept of palliative care is like a new-born baby who needs a lot of attention. Lynch, Connor \& Clark [7], identified that the ratio of palliative services in Pakistan in relation to population is 1:90 million. Furthermore, the burden of chronic illness in Pakistan is very high. According to the Global burden of diseases (2010), it is estimated that by 2025 there will be 3.9 million deaths in people aged between 30 to 69 years in Pakistan due to NCDs including cardiovascular diseases, respiratory diseases, cancer, diabetes mellitus and mental health illnesses. Furthermore, lack of resources, lack of qualified personnel, and lack of awareness are other challenges that delay the growth of palliative care in Pakistan.

\section{Nurse Role in Palliative Care}

"I will remember that I do not treat a fever, a chart, a cancerous growth, but a sick human being, whose illness may affect the person's family and economic stability. My responsibility includes these related problems, if I am to adequately care for the sick".-Hippocratic Oath, Modern Version.

The above oath is a reminder for nurses to care for the patient in a holistic way. The aim of comfort care is to prepare the patient and the family for the end-of-life stage. Comfort care concepts bring many ethical issues for nurses and in such situation; nurses need to work as an advocate. Nurses, the patient and the family have to work for one common goal and that is of providing comfort to the patient. Allow the patient to express their wishes in collaboration with family members is also required. Understanding of patient desire of living at home is very important. Nurses need to put energy to make the family understand the concept of futile care. End-of-life stage concerns need to be discussed openly and honestly in the context of cultural customs, because discussion on such matters is taboo in our culture. Singh and Harding recommended that more studies are required to understand the culture value of death and dying for South Asian patients responding to the growing needs of palliative care in this region [8]. Ongoing reassurance to the patient and the family that comfort care at home does not mean that the patient will be deprived of any required medical treatment [9]. Moreover, arrangement of basic needs at home is also the responsibility of the medical team e.g., proper bed, oxygen supply, suctioning facility, etc. Though at present home health care services and palliative clinics are at the growing stage, but awareness about this is important while caring for the patient at home [10] Finally, the patient and the family must be treated with dignity and security.

\section{Conclusion}

Home-based palliative services are at a growing stage in Pakistan. Nurses can play a significant role in promoting this model. The important precondition for successful palliative care is a triangular relationship of the nurse, the patient and the family. Caring for the dying patient at home is a strong decision that would be favorable for all. The aim of all interventions should be comfort care and preparedness for the patient's end-of-life stage.

\section{Acknowledgment}

I would like to express my sincere gratitude to Dr Rozina Karmaliani, Professor at Aga Khan University-School of Nursing and Midwifery Karachi for her continuous support, motivation and guidance.

\section{References}

1. Billings JA, Krakauer EL (2011) On patient autonomy and physician responsibility in end-of-life care. Arch Intern Med 171: 849-853.

2. Bailey FA, Harman SM, Bruera E, Arnold RM, Savarese DM (2014) Palliative care: The last hours and days of life. UpToDate.

3. Ferrell B, Coyle N (2002) An Overview of Palliative Nursing Care: Studies tell us that most people fear a protracted, painful death; unfortunately, this is what many experience. Palliative nursing care seeks to change this. This new series challenges nurses to think differently about caring for people when cure isn't possible. Am J Nurs 102: 26-31.

4. Field MJ, Cassel CK (1997) Approaching death: improving care at the end of life. Washington (DC): National Academy Press.

5. Khan RI (2016) Palliative care in Pakistan. Indian journal of medical ethics.

6. Lynch T, Connor S, Clark D (2013) Mapping levels of palliative care development: a global update. J Pain Symptom Manage 45: 1094-1106.

7. Paulus SC (2008) Palliative Care: An Ethical Obligation. Markkula Center for Applied Ethics, Santa Clara University.

8. Singh T, Harding R (2015) Palliative care in South Asia: a systematic review of the evidence for care models, interventions, and outcomes. BMC research notes 8: 172 .

9. Slote M (2007) The ethics of care and empathy. Analysis 69: 190-192.

10. World Health Organization. Cancer pain relief and palliative care (1990) Geneva: WHO: Technical report series 804. 